\title{
Validity and Reliability Test of Construction of Power Legs Test Measurement
}

\author{
Mona Fiametta F*, Firas J, Hadi Sartono, Dudung Hasanudin Cholil \\ Sport Coaching Education Program \\ The Faculty of Sport and Health Education \\ Universitas Pendidikan Indonesia \\ *monafiametta@upi.edu
}

\begin{abstract}
In order to get a maximum of peak performance, we coaches are not allowed to close themselves from the development of the current era because if the coaches close themselves we will lack the creative things we can make for athletes to support the achievements that the coach wants, for example of making measuring instrument. A variety of measuring instrument with their advantages and disadvantages are made to serve as a reference for coaches and many others. Measuring instrument that researchers find is Jump Power Meter, Force Plat, Jump DF which in a fact requires a very high expenditure if done for the test periodically in the periodization of training, with the result that researchers consider having to do research on the construction of power test measurement. The method used in this research is the research and development method. The sample of this research is 30 students of Sport Coaching Education among them 20 males and 10 females. Data retrieval uses the construction of a measuring instrument that has been created in such a way and to determine its validity and reliability of the researchers compared with the vertical jump test. The results concluded that the measurement of power legs tools can be used as a measuring tool of power leg because this power test has validity and reliability with a very strong correlation coefficient.
\end{abstract}

Keywords-construction measurenemt; leg; power; reliability; test validity

\section{INTRODUCTION}

Having a great achievement is every athlete's dream. There are many factors that may lead to a great achievement that cover intern and extern factors. Intern factor such as technique, physical, and psychological preparation are as important as extern factors that cover facilities and coaching system to help athletes' achievement. Along with today's rapid sport development and its technology, research on sports keep developing as an attempt to promote development in sports and to give a better coaching system by using scientific approach. So as to achieve maximum result and performance, the coaches are expected to be open to the development of technology. This attitude is important to make them more creative in helping the athletes perform the expected achievements.

Paulus and Dikdik mention that athletes' maximum performance is the result of a series of coaching system and exercise periodization that have been carefully arranged by the coaches so that the athletes will be able to achieve the peak performance as has been planned [1]. To this case, they noted that :

"The exercise periodization refers to exercise and competition planning that has been previously and carefully arranged so that the peak performance can be achieved in the time that has been predicted beforehand."

An athlete's peak performance is mainly supported, one of them by her/his physical condition. Bompa asserts that physical condition plays significant role to make great achievement as physical condition will be a valuable asset for an athlete to have improve their endurance, fitness, and success in making great achievement [1]. It is further stated that physical preparation is one essential factor that needs to be notified and considered among many other factors to get peak performance and achievement and someone can be claimed in a good physical condition when s/he is able to do physical activities without any extreme exhaustion.

In any kinds of sports, the issue about parameter test will always deal with four vital components of physical bio motor that cover flexibility, speed, strength, and endurance. All these four components should tested to know the capability of each athlete whose results can be made as starting point to create a coaching program.

From all the aforementioned physical condition components, the study tries to focus on strength component, which consists of two more specific components as described that "Strength consists of two more specific components namely maximum strength or speed strength and strength endurance" [2].

According to Harsono, "Power is defined as a product of from speed strength that is referred to muscles power to give maximum strength in relatively a short time" [3]. Almost all sports need this kind of strength.

The study limits the focus on legs power. Based on the literature review, there have been some measurements of power legs and power endurance of legs muscles nowadays. They cover : 1) Vertical Jump; 2) Standing Broad Jump; 3) 3 Hop Jump; 4) 5 Hop Jump; 5) 10 Hop Jump; 6) Endurance Jump 30 Second. These are used to measure legs power and power endurance of legs muscles. 
Problem comes up when the researcher, as an athlete and a coach, once wanted to test legs power, he faced some obstacles in doing vertical jump test because vertical jump test hasn't specified on particular sport and because the unavailability of space to do the test in open space or public facilities. It is important to be known that a vertical jump test needs a wall as s supporting facility as it's used to attach the scale of measurement (in meter) to measure the result of one's jump. When the researcher wants to do physical test, he faces some difficulties due to the unavailability of wall to support the vertical jump test. Departing from this problem, the researcher initiates to make a measurement tool to measure legs power for a condition when vertical jump test is no longer considered practical to be conducted.

Not all power legs test can be done through vertical jump test because each kind of sport may need a more specific power legs test for example to measure one momentum when jumping that can be measured by a more specific legs activity not only through the touch of finger tips. Another factor is dealing with one's shoulder and arms flexibility that may affect the jumping result. Besides the length of arms of each person is also different so that it may also have an effect on the result of power legs test that also use arms to do the test.

Actually, the measurement tool that is going to be made has been introduced to public and has been tried out in the level of region. However, the tool is still considered not feasible and its validity and reliability haven't been tested thoroughly. Based on several considerations, the researcher along with experts discussed to test the validity and reliability of the measurement tool, but further the researcher planned to make the tool has better values in terms of its economic, aesthetic, and usage feasibility aspect.

\section{METHOD}

The study was set as a research and development study (R\&D). R\&D, according to Sugiyono is defined as "a method of research that is aimed to make certain product and to further test its effectiveness" [4]. In addition, it is also stated that so as to make particular product, the study needs to be conducted based on the need analysis and the product' effectiveness needs to be tested to make the product beneficial for society in general [4]. The result of the study is a tool for measuring power legs that makes Research and Development method suits this study.

\section{RESULT AND DISCUSSION}

After conducting testing to 30 samples which consists of 20 males and 10 females, the result of construction of power legs measurement tool testing is described as follows:

\section{A. Construction of Power Legs Measurement Tool Has Strong Degree of Validity}

Based on the result of validity testing by interpreting the correlation coefficient, it can be concluded that construction of power legs measurement tool can be used as a tool of measurement since it meets the requirements of validity.
This study tries to seek score of validity of the tool by comparing result of the first jump by using the construction of measurement tool with the result of the first jump of vertical jump test. The result shows that score of correlation coefficient of the measurement tool can be interpreted as very strong, for male category $\mathbf{r}=\mathbf{0 , 9 1}$ and $\mathbf{r}=\mathbf{0 , 9 2}$ for female category. This strong degree of validity was gained since it shows similar results to those by using vertical jump test. This strong validity is also due to the suitable height and criteria of the measurement tool to the needs of some sports that demand explosive movement.

The construction of measurement tool is able to describe power legs ability since it is able to show character of power as described by Sidik that power is referred to mescles ability to drive their maximum strength in a short period of time [5]. After having data analyzed, it can be concluded that the construction of measurement tool of power legs can be used as power legs test of some sports to measure some explosive movements.

This tool construction works purely based on the legs of the sample. That is why, samples need to be really focused when they jump to get high level of explosive movement to get optimum result. Samples with lack of focus on their legs will not have high level of explosive movement although they jumpy really high. To sum up, the construction of tool to measure power legs has string and significant validity to be used as a power legs measurement tool.

\section{B. Construction of Measurement Tool of Power Legs Has a Strong Degree of Reliability}

The study is also aimed to seek the reliability score of the tool measurement. The results of testing also describes that the construction of tool to measure power legs fit the requirement of reliability due to its strong constancy and reliability to the correlation coefficient. The score of reliability of the tool has very strong level of correlation coefficient, with $\mathbf{r}=\mathbf{0 , 8 2}$ for males category and $\mathbf{r}=\mathbf{0 , 9 3}$ for females category. A score of constancy and reliability was gained through 3 times data collection by giving power legs test whose result in each category reveals that the tool can be used to measure physical bio motor components of power legs.

This strong constancy and reliability score was gained because the test by using construction of measurement tool make relatively same result with vertical jump results (in the second and the third of jumping), and even some samples make jumping score that keeps increasing. The results shows that the degree of reliability for male category $\mathbf{r}=\mathbf{0 , 8 2}$ and $\mathbf{r}=\mathbf{0 , 9 3}$ for female category. The degree of reliability of male category is slightly lower than score for female category because some sample in male category can't give their optimum jump due to the inefficient of movement that made them failed in producing explosive movement and that made their result is different from the previous jumping result.

This construction of tool to measure power legs can be considered reliable since it has been tested for several times and the revised and be retried to make the tool works well when it is used by the wider samples. Some obstacles in making the tool construction is dealing with strap attached to 
the samples' hip sometimes slacken when they have jumped. This makes the tester should tighten the strap so that a maximum result can be gained. Another factor is also dealing with the hook that connects the strap to the belt that needs to be fixed. The same case to be fixed is on the result displayer tool that hasn't worked really well that makes the tool can't show the actual jumping result. Luckily, these obstacles can be overcome optimally that makes the construction of measurement tool has a high degree of reliability.

The process of making the tool was conducted to several phases and has been tested for several times to achieve the perfect construction of the tool. In designing the tool, the researcher consulted to the expert in design, in this case Kang Hambali, to help him in designing a tool of measurement that has the same concept as the concept of the researcher. Further, the researcher also consulted to the expert in sports who also acted as the supervisor of the thesis, Drs. Dudung Hasanudin $\mathrm{Ch}$. to get advices and approval of the tool construction in terms of its function to measure power legs, whether or not the tool can measure what it wants to be measured (validity).

This tool construction can be concluded to have a strong and significant level of validity and reliability to measure power legs not only when it increases but also when the power decreases due to several factors, including physical condition that may affect. This finding can be used as a base to do further research under the same topic.

The researcher also tried to look for related research with similar finding to have a study comparison in making construction of measurement tool. As the result, several related research have been conducted by Niluh Ketut N.P, a student majoring IKOR FPOK UPI whose paper entitled "Developing Tool of measurement of time hand reactions based on Microcontroller." Her study describes that the measurement tool of time hand reactions based on Microcontroller can work in one minute with maximum score 100 and the result of the score is displayed in the LCD and it stops automatically in 60 seconds. The tool of measurement has functions to measure time of hands reaction, to improve the speed of hand reaction, and to train eyes and hands coordination. Based on try out to 30 samples that consists of 15 males and 15 females, it was revealed that score for male is higher than score of females. This tool of measurement has validity score 0,60 and reliability score 0,624 . This is due to several affecting factors that cover untested measurements, aspects of the tool that needs to be fixed in terms of its design and etc.

\section{CONCLUSION}

Based on the statistical data analysis in terms of validity and reliability, it can be concluded that the measurement tool of power legs has a strong and significant score of validity and reliability. This tool of measurement is then named Jump Power Leg.

Based on the findings, some conclusion can be drawn as follows :

- The Jump Power Leg measurement tool is proven by the study to have a strong validity that makes the tool valid and whose results can be accounted for its accuracy.

- The Jump Power Leg measurement tool is proven by the study to have a strong reliability that makes the tool reliable and whose results can be accounted for its accuracy.

To sum up, the findings of the study have answered the research question since the tool that is developed, in this case, Jump Power Leg has been proven to have strong and significant validity and reliability that can be seen by its strong correlation coefficient validity for males $\mathbf{r}=\mathbf{0 , 9 1 9}$ and $\mathbf{r}=\mathbf{0 , 9 2 8}$ for females and reliability correlation coefficient $\mathbf{r}=\mathbf{0 , 8 2 7}$ for males and $\mathbf{r}=\mathbf{0 , 9 3 7}$ for females category.

\section{REFERENCES}

[1] S.D.Z. Satriya, and I. Imanudin, Metodologi Kepelatihan Olahraga Bandung: Buku Ajar FPOK UPI, 2010.

[2] Satriya et al. Bahan Ajar Teori Latihan Olahraga. Bandung: CV. NURANI, 2014

[3] Harsono, Latihan Kondisi Fisik. Bandung, 2001.

[4] Sugiyono, Metode Penelitian Pendidikan Pendekatan Kuantitatif, Kualitatif, dan R \& D.(edisi ke-21). Bandung: Alfabeta, 2014.

[5] D.Z. Sidik, Pembinaan Kondisi Fisik (Dasar dan Lanjutan). Bandung: Buku Ajar FPOK UPI, 2011 